

\section{REVISTA \\ TEORÍA Y PRÁCTICA \\ DE LA \\ ARQUEOLOGÍA HISTÓRICA LATINOAMERICANA}

ISSN: 2250-866X (impreso) | ISSN: 2591-2801 (en línea)

AÑO VIII, VOLUMEN 9, PRIMAVERA DE 2019

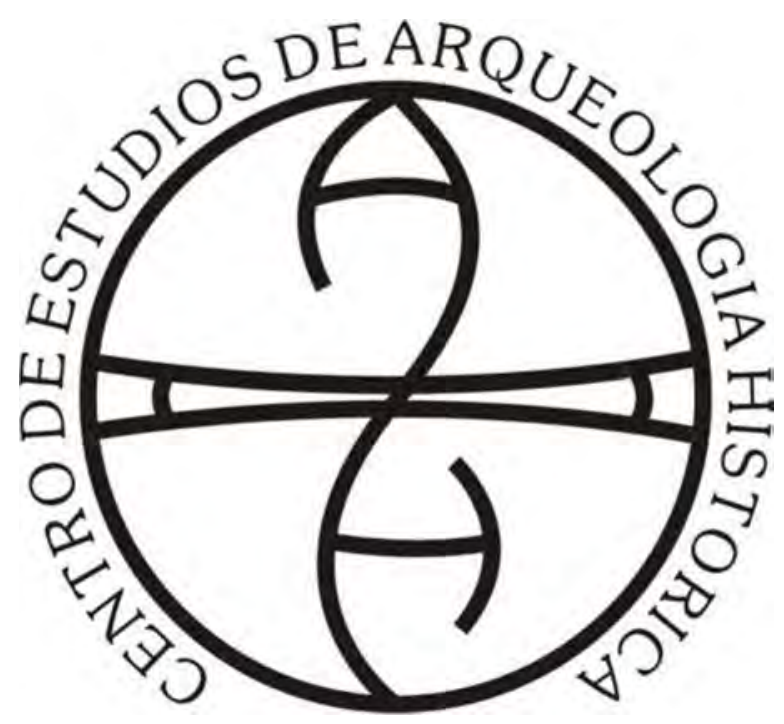

CENTRO de Estudios de ARqueOlOGía HistóricA

FACULTAD DE HUMANIDADES Y ARTES | UNIVERSIDAD NACIONAL DE ROSARIO 
(Universidad Nacional de Rosario, Universidad Nacional de Río Cuarto,

Universidad Nacional de San Juan, Universidad de la República, Universidad Nacional de Trujillo)

\author{
AUTORIDADES DE LA UNIVERSIDAD NACIONAL DE ROSARIO \\ RECTOR: Lic. Franco Bartolacci \\ VICE-RECTOR: Od. Darío Macía \\ SECRETARIO GENERAL: Prof. José Goity \\ SECRETARIA ACADÉMICO Y DE APRENDIZAJE: Dr. Marcelo Vedrovnik \\ SECRETARÍA DE CIENCIA TECNOLOGÍA E INNOVACIÓN \\ PARA EL DESARROLLO: Ing. Guillermo Montero.
}

\author{
AUTORIDADES DE LA FACULTAD DE HUMANIDADES Y ARTES \\ DECANO: Prof. Alejandro Vila \\ VICEDECANA: Prof. Marta Varela \\ SECRETARIA ACADÉMICA: Dra. Marcela Coria
}

\author{
AUTORIDADES DEL CENTRO DE ARQUEOLOGÍA HISTÓRICA \\ DIRECTORA: Dra. Ana Rocchietti \\ SECRETARIA: Prof. Nélida de Grandis \\ PROSECRETARIA: Lic. Marianela Bizcaldi
}

DIRECTORAS - EDITORAS:

Dra. Ana Rocchietti y Prof. Nélida De Grandis

SECRETARIA DE EDICIÓN: Dra. Irene Dosztal

Este número es co-edición de las ponencias

del VIII Congreso Nacional de Arqueología Histórica (2018) entre:

Centro de Estudios en Arqueología Histórica: Directora Ana Rocchietti

Centro de Estudios en Arqueología Regional: Director Fernando Oliva

Centro de Estudios en Arqueología Subacuática: Directora Mónica Valentini

Departamento de Arqueología, Escuela de Antropología: Director Fernando Oliva
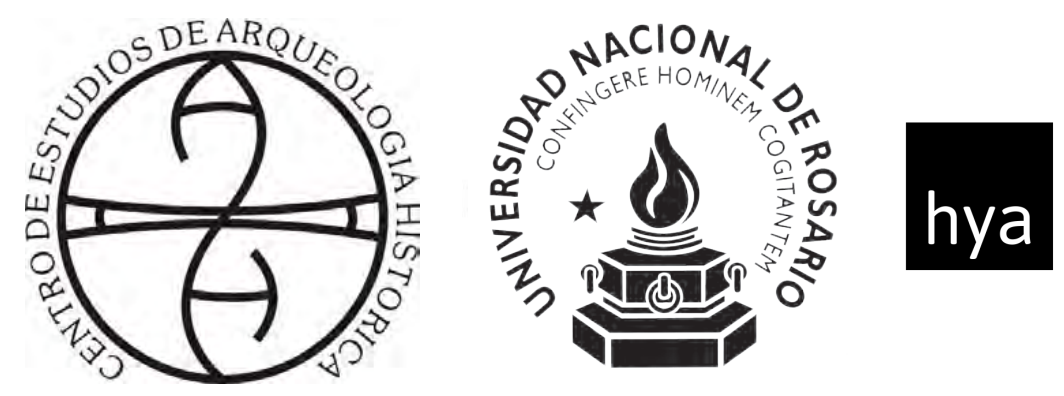

Facultad de Humanidades

y Artes_UNR
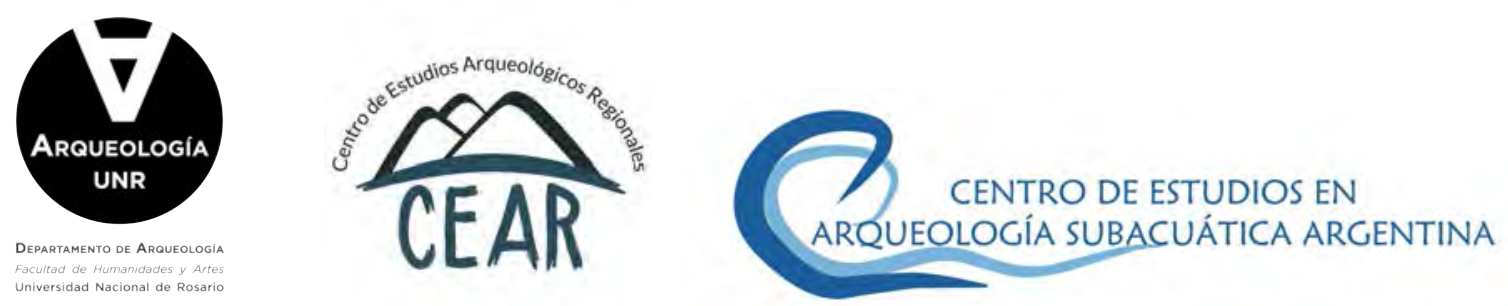
Comité Permanente de los Congresos Nacionales de Arqueología Histórica

Dr. Daniel Schávelzon (Universidad Nacional de

Buenos Aires)

Prof. María Teresa Carrara (Universidad Nacional de Rosario)

Prof. Carlos Baldassarre (Museo Municipal de Río

Grande, Tierra del Fuego) in memoriam

Dr. Mariano Ramos (Universidad Nacional de Luján, CONICET)

Dr. Horacio Chiavazza (Universidad Nacional de Cuyo)

Dra. Ana María Rocchietti (Universidad Nacional de

Rosario, Universidad Nacional de Río Cuarto)

Lic. Facundo Gómez Romero (Universidad Autónoma

de Barcelona)

\section{Comité Científico}

Dra. Tânia Andrade Lima (Universidade Federal do Rio de Janeiro)

Prof. Réginald Auger (CELAT/Département des

Sciences Historiques, Université Laval, Canadá)

Dr. Roberto Bárcena (Universidad Nacional de Cuyo, CONICET)

Dra. Marta Bonaudo (Universidad Nacional de Rosario, CONICET)

Dr. Leonel Cabrera (Universidad de la República, Uruguay)

Dr. Luis María Calvo (Universidad Católica de Santa

$\mathrm{Fe})$

Prof. Juan Castañeda Murga (Universidad Nacional de

Trujillo, Perú)

Dr. Carlos Ceruti (Museo de Ciencias Naturales y

Antropología "Prof. Antonio Serrano”. Paraná)

Dr. Horacio Chiavazza (Universidad Nacional de Cuyo)

Dra. Silvia Cornero (Universidad Nacional de Rosario)

Prof. Pedro Paulo Funari (Universidade Estadual de

Campinas, Brasil)

Lic. Jorge A. Gamboa Velásquez (Universidad Nacional

Santiago Antuñez de Mayolo, Perú)

Dr. Eduardo Alejandro García (Universidad Nacional de

San Juan, CONICET)

Prof. Nélida De Grandis (Universidad Nacional de

Rosario)

Dr. Juan Bautista Leoni (Universidad Nacional de

Rosario, CONICET)

Dra. Amancay Martínez (Universidad Nacional de San

Luis)

Dra. Catalina Teresa Michieli (Universidad Nacional de

San Juan, CONICET)

Lic. Fernando Oliva (Universidad Nacional de Rosario)
Ing. Adrián Pifferetti (Universidad Tecnológica Nacional Regional Rosario)

Dr. Mariano Ramos (Universidad Nacional de Luján, CONICET)

Dra. Ana María Rocchietti (Universidad Nacional de Rosario)

Dr. Daniel Schávelzon, (Universidad Nacional de Buenos Aires, CONICET)

Dra. Carlota Sempé (Universidad Nacional de La Plata)

Dr. Mario Silveira (Universidad Nacional de Buenos

Aires)

Dra. Silvia Simonassi (Universidad Nacional de Rosario)

Dra. Alicia Tapia (Universidad Nacional de Buenos Aires, Universidad Nacional de Luján)

Lic. Mónica P. Valentini (Universidad Nacional de Rosario)

Agrim. Benito Vicioso (Universidad Nacional de Rosario)

\section{Evaluaron este volumen}

Roberto Bárcena, María Teresa Boschin, Leonel Cabrera, Ulises Camino, María Rosa Carbonari, Carlos Ceruti, Horacio Chiavazza, Nicolás Ciarlo, Silvia Cornero, Eduardo Crivelli, Javier García Cano, Martín Gentinetta, María Laura Gili, Carlos Landa, Matilde Lanza, Melina Malandrino, Sebastián Pastor, Victoria Pedrotta, Josefina Piana, Mercedes Podestá, Mariano Ramos, Daniel Schavelzon, Diana Tamburini, Mónica Therrien, Mónica Valentini y María Teresa Boschin

\section{Diseño y diagramación}

Eugenia Reboiro

(eugenia.reboiro@gmail.com)

\section{Curadoría}

Ana Rocchietti e Irene Dosztal

Foto de tapa: Material arqueológico, del texto de Tapia et al.

\section{Propietario responsable:}

Facultad de Humanidades y Artes, Universidad Nacional de Rosario Centro de Estudios de Arqueología Histórica

Entre Ríos 758. Rosario, provincia de Santa

Fe (2000). Argentina.

Telf.: +54 (0341) 4802670

E-mail: ceahunr@gmail.com

Decreto Ley 6422/57 de Publicaciones

Periódicas 


\section{Índice}

Editorial

El origen del patrimonio histórico y su conservación integral en la contemporaneidad.

Yanina Aguilar

Prospección de basurales históricos de la ciudad de Rosario.

Soccorso Volpe y Gustavo Fernetti

Desconstrucción de un paisaje urbano. El Montevideo del extramuros colonial, aportes de la arqueología a su identidad actual. Ana Gamas

La Calota de Ameghino: reconsiderando un viejo tema desde la arqueología histórica.

Daniel Schávelzon

Análisis zooarqueológico de los restos hallados en una estructura sanitaria vinculada a momentos tempranos del actual barrio de Belgrano .71 Mario Silveira, Horacio Padula, Ricardo Orsini y Eva Bernat

La medida del tiempo: el reloj solar jesuita de La Cruz, provincia de Corrientes.

Fernando Oliva y María Cecilia Panizza

Sitio La Quinta: arqueología rural de campos serranos.

Flavio Ribero

Si no hay tabaco que no se note. Prácticas fumatorias en el fortin La Perra (1883-1885), La Pampa.

Alicia Tapia, Virginia Pineau y Melisa Ayelén Auge

El uso del tabaco y las pipas de caolin (clay pipes) en la frontera sur y oeste de la provincia de Buenos Aires en el siglo XIX.. .127

María del Carmen Langiano y Julio Fabián Merlo 
Patrimonio natural, urbano y arquitectónico de la costa en Mar del Plata. Federico Negroni

Huellas urbanas.

Ezequiel Serrot

Paisaje y patrimonio. La industria taninera en el siglo XX.

Provincia de Santa Fe.

Cristina Pasquali, Paola Milicic y Lara Ferré

Los desafíos de las arqueologías históricas latinoamericanas.

Andrés Zarankin

Sellos entre escombrales. Las lozas en el registro urbano

del Área Fundacional de Mendoza (siglo XIX y principios del siglo XX)

Lorena Puebla y Horacio Chiavazza

Evolución edilicia de la Plaza de Mayo de la Ciudad

de Buenos Aires (1580-1853).

Nicolás Ferrino

Gestión patrimonial en el rescate arqueológico y futuro Museo de Sitio

en Moreno 550, Ciudad Autónoma de Buenos Aires, Argentina.

María Eva Bernat, Ricardo Orsini, Horacio Padula y Mario Silvera 


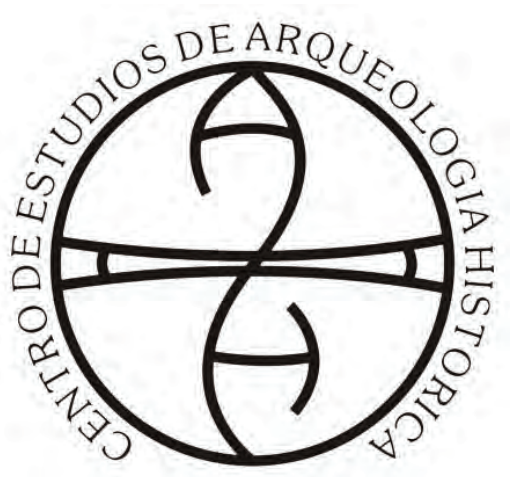

Centro de Estudios de Arqueología Histórica

Universidad Nacional de Rosario
Teoría y Práctica de la Arqueología Histórica

Latinoamericana | Año VIII. Vol. 9 | 2019

Revista del Centro de Estudios de Arqueología

Histórica, Facultad de Humanidades y Artes,

Universidad Nacional de Rosario

https://teoriaypracticaah.unr.edu.ar/index.php/index

ceahunr@gmail.com

ISSN en línea: 2591-2801

ISSN versión impresa: 2250-866X

\title{
DESCONSTRUCCIÓN DE UN PAISAJE URBANO EL MONTEVIDEO DEL EXTRAMUROS COLONIAL, APORTES DE LA ARQUEOLOGÍA A SU IDENTIDAD ACTUAL
}

\author{
Ana Gamas*
}

\section{Resumen}

La desmemoria a través del tiempo puede llegar a provocar la pérdida de información de todas aquellas personas, construcciones materiales y sociales que hicieron posible finalmente la conformación de un espacio geográfico urbano, como es para este caso el departamento de Montevideo (Uruguay). Esas memorias, muchas de ellas aún presentes han presenciado el cambio vertiginoso de las décadas; en contraste de ello, se encuentran los más jóvenes habitantes de los ahora barrios centro-periféricos del departamento, los cuales en su gran mayoría, se encuentran ausentes de estas memorias colectivas. De la historia compartida de los barrios se sabe muy poco, solo algunos investigadores con profusas ansias de rescatarla del olvido, conocen y estudiaron parte de la misma; esto permitió la materialización de buena parte de la bibliografía que se maneja a la hora de investigar un área urbana en la capital oriental. Repetidas veces se hace mención cuando se habla de Montevideo del proceso fundacional dentro de la plaza fortificada; pero cabe aclarar también, que la Jurisdicción de aquel territorio abarcaba límites más extensos que los actuales. Comprendía, las orillas del Río de la Plata entre la desembocadura del arroyo Cufré hasta las sierras de Maldonado, y al Norte la Cuchilla Grande o albardón que servía también de camino. Si bien el discurso inicia generalmente en una fecha posterior, es en 1717 cuando el Rey Felipe V de España e Indias, ordena a Don Bruno Mauricio de Zabala (Gobernador del Río de la Plata) a fortificar los parajes de Maldonado y Montevideo. En 1726 Don Pedro de Millán fija la jurisdicción de la ciudad, el ejido y propios, repartiendo los primeros solares en lo que conocemos como Ciudad Vieja y chacras sobre las márgenes del arroyo Miguelete. El trazado de San Felipe y Santiago estuvo a cargo del Cap. Domingo Petrarca en 1730, diseñando la ciudad en líneas generales bajo las Leyes de Indias. La corona española entendía a la ciudad como una unidad económica e integradora donde se hallaba la ciudad-puerto como

* Licenciada en Ciencias Antropológicas (especialización Arqueología) y Técnica Museóloga. Facultad de Humanidades y Ciencias de la Educación. Universidad de la República. Montevideo- Uruguay. anagamas@arqueogestion.com.uy 
Teoría y Práctica de la Arqueología Histórica Latinoamericana | Año VIII. Vol. 9 | 2019

ISSN en línea: 2591-2801 | ISSN versión impresa: 2250-866X

casco urbano y un espacio circundante que abastecía de alimentos, donde se hallaban las quintas y/o chacras (donde se cultivaban legumbres, hortalizas, granos y frutos) y estancias (que abastecían de ganado). Pero por alguna razón se ha perdido la memoria de estas zonas que se hallaban conectadas a la ciudad de intramuros por medio de caminos. Estos se abrían desde la ciudad amurallada hacia las zonas más abiertas y fueron ubicados en la parte alta del relieve, siendo sus trazados iniciales de tierra. Con el correr de los años muchas de estas vías de transporte se fueron transformando en lo que hoy conocemos como avenidas principales. Generalmente se considera como núcleo histórico a la Ciudad Vieja, eje central y testigo incansable de los cambios y avatares, de luchas y pactos de paz, de construcciones y desconstrucciones desde el primer cuarto del s. XVIII. Estos caminos permitieron el asentamiento de aldeas, villas y poblados; que poco a poco sentaron las bases para la conformación de los barrios actuales. Quienes transitan estas avenidas, desconocen la historia de los mismos y el porqué estos barrios conservan aún una memoria tangible; la cual se visualiza en hallazgos materiales de más de un siglo y que hacen a la identidad de los barrios. Este trabajo pretende abordar aquellas zonas alejadas y los caminos que a las mismas conducen. Con una mirada desde la investigación arqueológica se intentará hacer una puesta a punto de estos remanentes de la historia tradicional. Al mismo tiempo se presenta el relevamiento de algunos sitios con vestigios materiales, con potencial interés para el estudio arqueológico. Las zonas de abordaje son un conjunto de barrios que se encuentran en el centro y hacia la periferia capitalina, los cuales presentan la pérdida de memoria tangible e intangible debido a los procesos urbanísticos.

Palabras clave: Arqueología Urbana-Montevideo-Identidad

\begin{abstract}
The forgetfulness through time can cause the loss of information of all the people, material and social constructions which finally made the building of an urban geographic space possible, as it is the case of the department of Montevideo (Uruguay). Those memories, many of which are still present, have seen the vertiginous change of decades; in contrast, we find the youngest inhabitants of the current centralperipheral neighborhoods of the department, most of whom have no collective memories. Little is known about the shared history of the neighborhoods. Just some researchers with profuse desires to rescue it from oblivion have known and studied part of it; this made it possible to materialize a good part of the bibliography used when investigating an urban area in the Uruguayan capital. Often when talking about Montevideo, the foundational process within the fortified square is mentioned, but it should also be pointed out that the jurisdiction of that territory encompassed more extensive limits than the current ones. It included the banks of the River Plate between the mouth of the Cufré stream and the hills in Maldonado and to the North the Cuchilla Grande hill range or islet which also served as a path. Although the speech generally starts at a later date, it is in 1717 when the King Felipe V of Spain and the Indies orders Mr. Bruno Mauricio de Zabala (Governor of the River Plate) to fortify the Maldonado and Montevideo sites. In 1726 Mr. Pedro de Millán establishes the jurisdiction of the city, the ejido and propios, distributing the first plots in what is known as Ciudad Vieja (Old City) and country houses on the edge of the Miguelete stream. Cap. Domingo Petrarca was in charge of the layout of San Felipe y Santiago in 1730, designing the city in general terms under the laws of the Indies. The Spanish crown understood the city as an economic and integrating unit where the city-port was the urban center with a surrounding area which provided food, where there were farms and/or country houses (where legumes, vegetables, grains and fruits were grown) and ranches (which provided livestock). But for some reason the memory of these areas which were connected to the walled city by means of roads has been lost. These spanned from the walled city to more open areas and were located in higher terrain with their layouts initially made of dirt. Over the
\end{abstract}


years many of these transport routes were transformed into what today we know as main avenues. The Ciudad Vieja (Old City) is generally regarded as the historical center, central axis and tireless witness of the changes and vicissitudes, of struggles and pacts for peace, of constructions and deconstructions since the first quarter of the 18th century. These roads allowed the settlement of villages and towns, which little by little laid the foundations for the current neighborhoods. Those who circulate through these avenues do not know the history of these neighborhoods and the reason why they still retain a tangible memory which is visualized in century-old material findings that play an important role in the identity of the neighborhoods. This work aims to deal with those remote areas and the roads leading to them. From the point of the archaeological research we will try to update these remnants of the traditional history. At the same time, a survey will be carried out of some sites which have material vestiges and a potential interest to archaeological studies. The areas included are a group of neighborhoods located in the center and towards the capital's periphery, which represent the tangible and intangible loss of memory due to urbanization processes.

Key words: Urban Archeology - Montevideo- Identity.

\section{Marco conceptual}

Se plantea un abordaje desde la arqueología urbana la cual posee ciertas características relacionada a los cambios en la trama urbana, su uso social y espacial. Proudfoot (como se citó en Ruiz \& Burillo, 1988) afirma que desde una perspectiva humana el territorio está comprendido por una dimensión social y se halla culturalizado, es allí donde transcurren las relaciones sociales. Zarankin (1994: 33) por su lado, menciona que "el medio urbano es, además de una respuesta adaptativa, un uso particular del suelo y el espacio". Por lo tanto, la relación geográfica de una urbe con su historia y el paisaje; estaría permitiendo dimensionar distintas escalas de estudio, sean estas a nivel material y/o simbólico, para comprender e identificar como surgieron y cuál fue su desarrollo hasta la actualidad.

En esta línea, la Arqueología ha definido al "paisaje" como una construcción histórico-cultural identificándose sincrónica y diacrónicamente con formas de comprender, organizar y utilizar los espacios sociales (Sánchez, 2010). La arqueología proporciona, de este modo, un enfoque multi e interdisciplinar para el estudio de las tramas urbanas; trabajando con otras ciencias en la comprensión de los vestigios culturales y en el estudio de "los procesos socio-culturales como fenómenos multifactoriales complejos" (Sánchez, 2009:165). En Sánchez, 2010)ํ․ Estos procesos son parte de la vida social, formando un constructo humano, que a través del tiempo y el espacio ordena las prácticas del habitar (Troncoso, 2008, Unesco, 2011) ${ }^{2}$.

Por lo tanto, la información arqueológica recuperada en contextos históricos urbanos, aun cuando lo examinado sean pequeñas ventanas, puede proporcionar aportes significativos relativos al conocimiento del uso del espacio, siendo que a partir de ellos es posible inferir procesos de transformación cultural (Valladão, 2001).

Se debe reconocer, a la hora de gestionar cualquier sitio y/o bien histórico-arqueológico, que el conocimiento del mismo inicia, a través del estudio y análisis profundo; esto es denominado, cadena de valor para una gestión integral del Patrimonio (Unesco, 2013). En esta línea la Unesco en su recomendación de $1976^{3}$ considera a una ciudad histórica, un grupo de construcciones y espacios que constituyan un asentamiento humano tanto en un medio urbano como rural y cuya cohesión y valor son reconocidos desde el punto de vista arqueológico, arquitectónico, estético o sociocultural. 
Teoría y Práctica de la Arqueología Histórica Latinoamericana | Año VIII. Vol. 9 | 2019

ISSN en línea: 2591-2801 | ISSN versión impresa: 2250-866X

\section{Proceso Fundacional}

A menudo la bibliografía divide a este proceso en período pre-fundacional y fundacional, abarcando los años de 1717-1726 y 1726-1730, respectivamente (de María, 1872; Bauzá, 1895; Bollo, 1897; Arredondo, 1951; Capillas, 1968; Azarola Gil, 1976; Reyes Abadie, 1977; Giménez, 2016). Siendo relevante para este trabajo tomar el concepto en conjunto y denominarlo como un proceso abarcativo de aproximadamente catorce años. Para $1717^{4}$ el Rey Felipe V, ordena a Zabala fortificar los parajes de Maldonado y Montevideo; aún así sus órdenes no fueron ejecutadas tras sucesivas reiteraciones hasta que en noviembre de 1723 los portugueses invaden el espacio de la bahía (de la Sota, 1965; Azarola Gil, 1976; Giménez, 2016).

Bajo el mando del Maestre Manuel de Freitas da Fonseca desembarca en Montevideo y comienza la construcción de un reducto fortificado. Para diciembre, Zabala concentra fuerzas en la guardia de San Juan (actual dpto. de Colonia) para expulsar a los portugueses. Para principios de 1724 los portugueses abandonan la bahía, luego de hallarse ante el aparato militar hispano que habían traído como refuerzo 500 indios tapes (Bollo, 1897); es para febrero cuando Zabala llega a Montevideo y ordena levantar una batería de seis cañones (de María, 1872; Bauzá, 1895; Arredondo, 1951; Azarola Gil, 1976; Giménez, 2016), llegando para ello a una cifra de 1000 indios tapes (de María, 1872; Bauza, 1895; Bollo 1897) de las reducciones (de María, 1872) para trabajar en las obras de fortificación. Terminada esta construcción en 1725, arribó tiempo después en noviembre de 1726 la fragata Nuestra Señora de la Encina (Azarola Gil, 1976) con los primeros colonos. Es el 24 de diciembre de ese año, considerado como fecha representativa por excelencia de la fundación de Montevideo. Posteriormente Millán fija la jurisdicción de la ciudad y reparte los solares entre los pobladores (de María, 1872). Para marzo de 1727 Millán fija el ejido y propios de la ciudad y comienza el reparto de chacras sobre el arroyo Miguelete. Dos años más tarde arriba el segundo núcleo de pobladores de las islas Canarias (Azarola Gil, 1976); y para diciembre de 1729, Zabala dispone la composición del Cabildo de la ciudad de Montevideo, comenzando así oficialmente la población sistemática del territorio oriental (de María, 1872; Bollo 1897; Bauzá, 1951).

\section{El Desarrollo Poblacional Alrededor de los Caminos}

La jurisdicción de Montevideo en el s. XVIII abarcaba la costa del Río de la Plata desde la desembocadura del arroyo Cufré hasta las sierras de Maldonado y al norte la Cuchilla Grande o albardón que sirve de camino y que divide las vertientes de los ríos San José y Santa Lucía de las que corren en la parte norte (Capillas, 1968). 


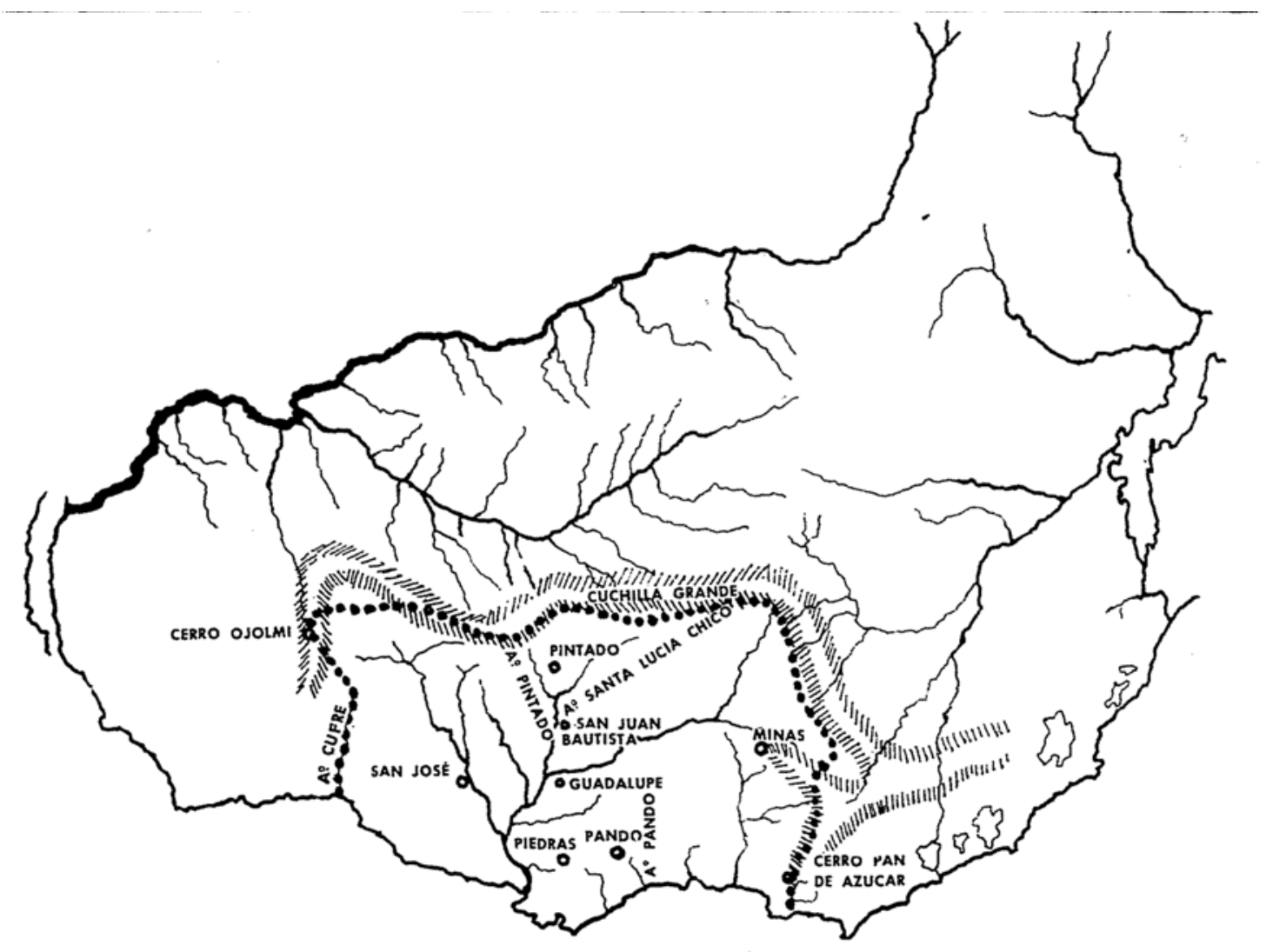

Figura I. Jurisdicción de Montevideo durante el s. XVIII, abarcaba “(...) entre la costa del Río de la Plata desde la desembocadura del arroyo Cufré hasta las sierras de Maldonado y al norte la Cuchilla Grande o albardón que sirve de camino a los faeneros de corambre y que divide las vertientes de los ríos San José y Santa Lucía de las que corren a la parte Norte”. Fuente: Capillas, 1968.

En 1730 en el plano de Petrarca es cuando aparece por primera vez el trazado de los caminos exteriores, siendo de ellos el denominado camino Real para el Pueblo, orientado de oeste a este, se abría en dos al nordeste a la altura de la calle Andes: A) un camino penetraba en la av. 18 de Julio y B) el otro se desviaba al nordeste hacia las calles Uruguay y Río Negro continuando hacia el sudeste, hasta la esquina de la calle Colonia y Yí, donde se abría nuevamente en dos: $\mathrm{B}^{1}$ ) camino de las chacras y la colina ${ }^{5}$ hacia el norte, unía al pueblo con las tierras para chacras, repartidas por Millán y lo conectaba también con la colina y B²) El camino para Maldonado hacia el este, tomando la dirección de 18 de Julio (Pérez Montero, 1942; Capillas, 1968). 


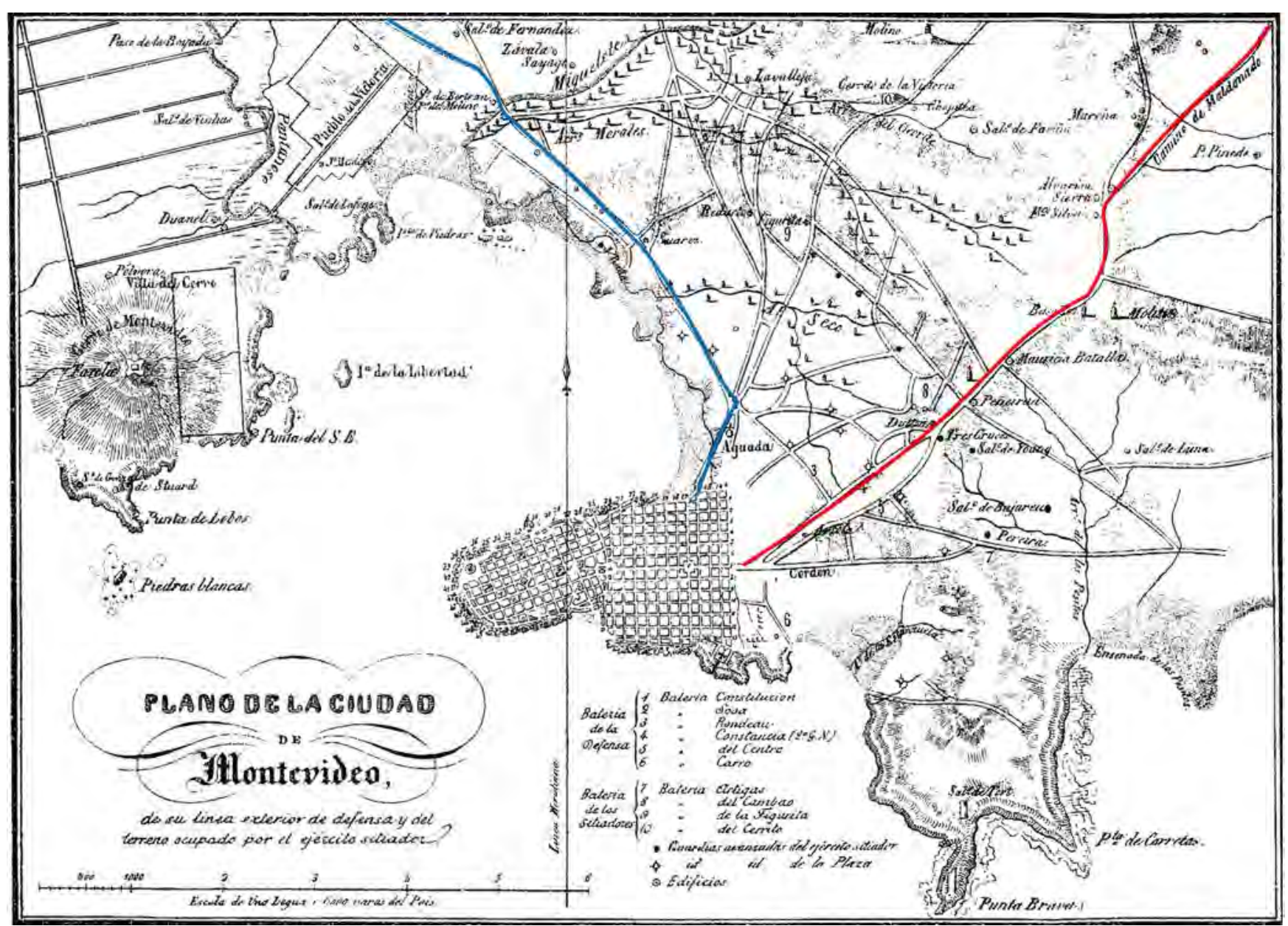

Figura II. "Plano de la ciudad de Montevideo, de su línea exterior de defensa y del terreno ocupado por el ejército sitiador”. Año 1844. En rojo se marca el antiguo camino a Maldonado y en azul el antiguo camino hacia Colonia, bordeando la bahía, pasando por la zona de Aguada y Paso Molino. Fuente: De María, 1883.

Los caminos Real y Maldonado estaban ubicados en la parte alta de la cuchilla correspondiendo a los trazados iniciales de los caminos de tierra. Del segundo a pocas cuadras de su punto de partida y a su izquierda salían otros dos caminos: el de las chacras con dirección norte y el de la costa de la bahía, que atravesaba los arroyos del Miguelete y Pantanoso, continuando después hacia el oeste por detrás del Cerro. Su continuación era el camino de la costa, de suma importancia en épocas coloniales, iba de oeste a este por el litoral del Plata en su primer tramo hasta el Atlántico, partiendo del real de San Carlos (Colonia) hasta Río Grande (Brasil), con escala en Montevideo (Pérez Montero, 1942; Arredondo, 1959). 


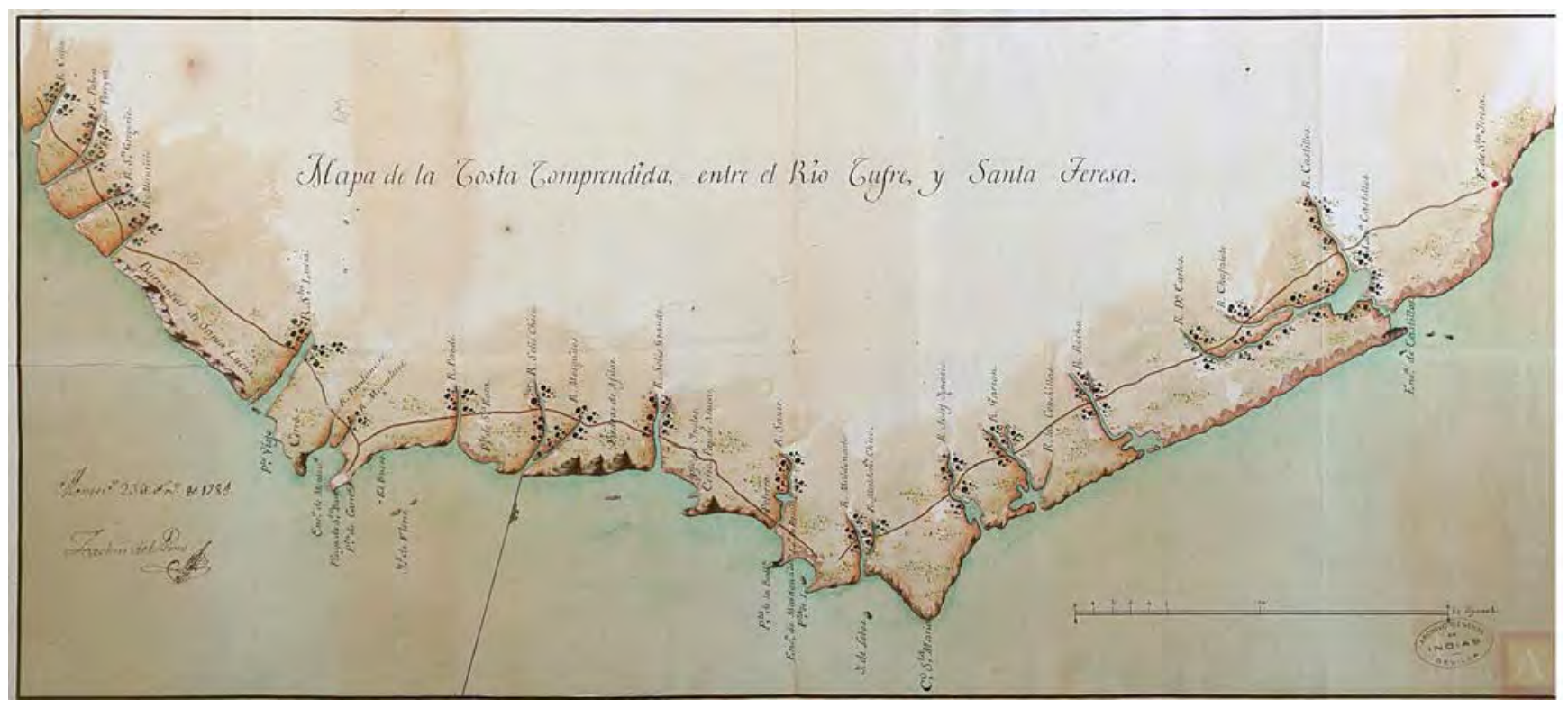

Figura III. Mapa de la Costa comprendida entre el Río Cufre y Santa Teresa. Firmado por Joaquín del Pino, 1785. Fuente: Archivo General de Indias. Cód. de Referencia:ES.41091.AGI/27.3//MP-BUENOS_AIRES,157. Recuperado de: http://pares.mcu.es/ParesBusquedas/servlets/Control_servlet (consultado abril 2019).

Pero las condiciones para la circulación por estos senderos no eran las mejores; la mayoría de las vías presentaban una ausencia de caminos, dejando en manos de algunos baqueanos el conocimiento del territorio y de sus dificultades sobre todo a nivel de cruces fluviales. Por otro lado, los caminos terrestres existentes se hallaban condicionados debido a su estado precario, propiciando una mayor afluencia de transporte por las vías fluviales (Baracchini y Altezor, 2008). Es recién con el reglamento para el establecimiento de postas a caballo (a partir de 1825) y posteriormente de diligencias que se estructurarían las vías terrestres a nivel de todo el país (Arredondo, 1959). Posteriormente, con el primer gobierno artiguista se hace efectiva la primera división departamental en el año 1816, permitiendo un primer ordenamiento territorial sistemático (Baracchini y Altezor, 2008).

Montevideo ha sido considerado históricamente desde sus inicios, como núcleo centralizador. Existiendo una idea generalizada, que la ciudad vieja fue el único recinto poblacional existente y bajo el cual se desarrolló el proceso fundacional del territorio a partir del s. XVIII. Es sin embargo, solo uno de los centros poblados que emergieron simultánea y sucesivamente durante el desarrollo demográfico de nuestro país. Siendo estos caminos una fase más, los cuales permitieron el asentamiento de aldeas, villas y poblados; conformando la base para barrios actuales, tales como: Paso Molino (de mediados del s. XVIII); Buceo (a partir de 1752 y 1789), Malvín (a partir de 1772); Manga (últimas décadas del s. XVIII); Villa de la Restauración (1851); Cerrito de la Victoria (de 1843-1851); Villa Colón- hoy Lezica (últimas décadas del s. XIX); Colón (a partir de 1873); Piedras Blancas (principios del s. XX); Jardines del Hipódromo ( primeras décadas del s. XX); entre otros. 


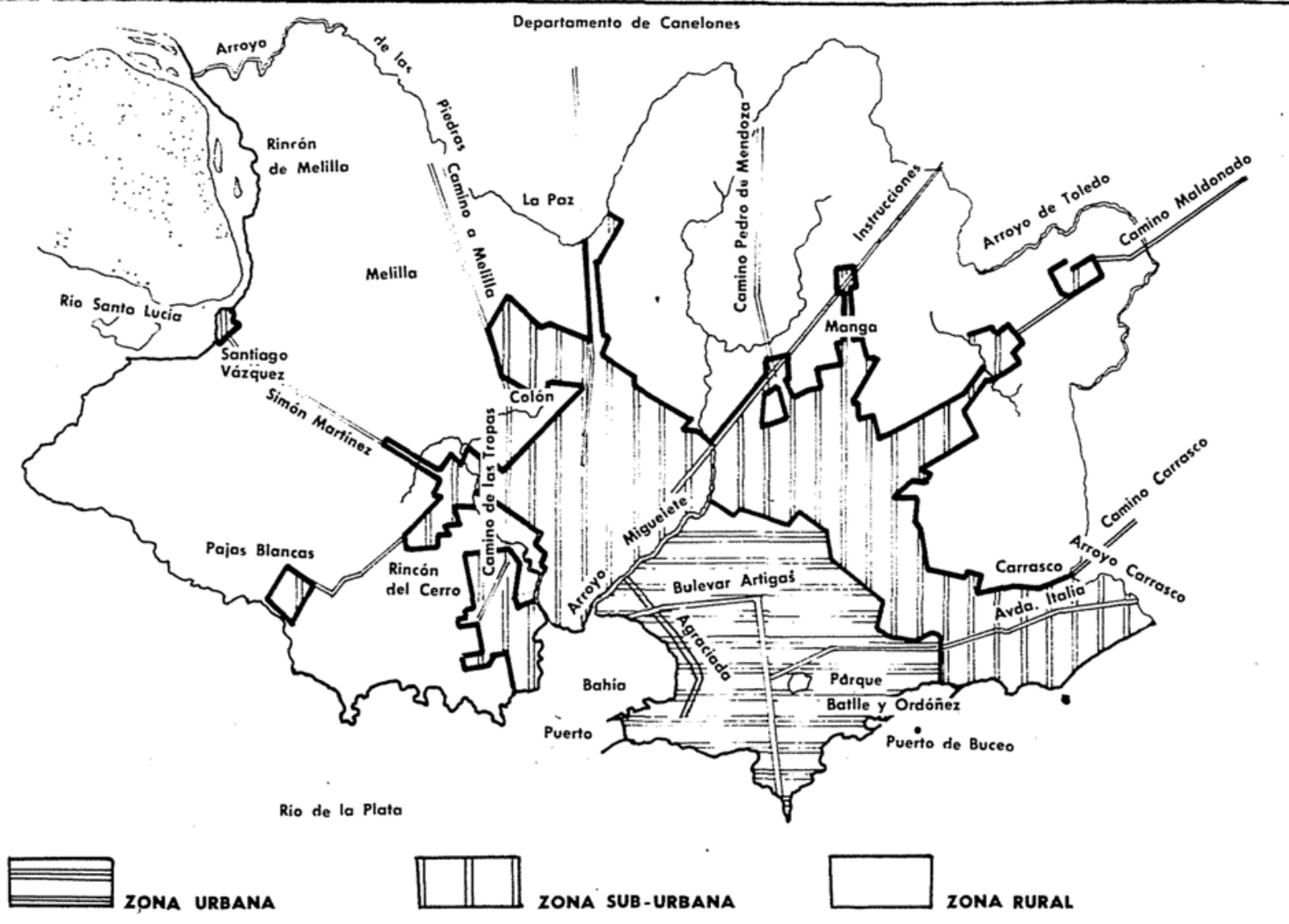

Figura IV. Límites de las zonas urbanas, suburbanas y rurales de Montevideo para mediados del s. XX. Fuente: Barrios Pintos, 1968, p.4

Las actuales avenidas fueron conformadas en base a los antiguos caminos coloniales, los cuales tenían de ancho cuarenta varas ${ }^{6}$ “(...) limitado en las vecindades de los centros poblados por zanjeados y cercos de pitas ${ }^{7}$, tunas, etc. y los caminos nacionales tuvieron ese mismo espacio al limitarse con los cercos de alambre” (Arredondo, 1959, p. 142). Quienes habitan y recorren la zona oeste y este de Montevideo, suelen desconocer el nacimiento, el desarrollo y la memoria que atesoran estos núcleos poblacionales. Vestigios culturales aún en pie guardan y ostentan por más de un siglo este legado, el cual se ha visto disminuido, debido al incremento sustancial de la urbanización en la capital y el área metropolitana desde fines de la década de 1980.

\section{Enfoque metodológico}

El objetivo-guía de este trabajo, es realizar una puesta a punto de los abordajes realizados desde la Arqueología en el departamento de Montevideo, desde la década de 1980 hasta la fecha (2019). Tomando el desarrollo poblacional periférico desde el punto de vista histórico, conjuntamente con la recopilación de trabajos bibliográficos publicados de corte arqueológico y de la información cedida por el dpto. de Arqueología de la Comisión de Patrimonio Nacional. A su vez se ejemplificará algunos trabajos de registro expeditivo en sitios donde se han observado vestigios materiales, los cuales presentan un potencial 
interés para la arqueología urbana, entendida ésta como "la arqueología de la ciudad moderna, actual y en funcionamiento” (Schávelzon, 2018). Las zonas de abordaje son principalmente, un conjunto de barrios que se encuentran en el centro y periferia capitalina. Se realizará además, una presentación de ejemplos, para ilustrar la necesidad de un abordaje más completo a la hora de recopilar información, lo que permitiría incursionar en potenciales líneas de investigación.

\section{Antecedentes de Estudios Arqueológicos en Montevideo}

La primera noticia bibliográfica sobre materiales arqueológicos encontrados en la zona, corresponde al Cerro de Montevideo y data de 1877. En ese año, el naturalista argentino Florentino Ameghino realiza una visita a diferentes paraderos y a partir de sus observaciones y de la colecta de material efectuada, publica sus Noticias sobre las antigüedades indias en la Banda Oriental señalando que “(...) los objetos recogidos son más que suficientes para demostrar que la Banda Oriental es seguramente una comarca rica en objetos prehistóricos” Ameghino (como se citó en Geymonat, 2016). Dichos materiales fueron enviados a la exposición mundial de París en 1878, para posteriormente ser integrados definitivamente, a la colección del museo de La Plata en la Rep. Argentina. Se tiene conocimiento para este momento de otros materiales donados y/o prestados por particulares para ser presentados en la exposición histórico-americana de Madrid de 1892, realizada en el marco del cuarto centenario del Descubrimiento de América.

Tabla 1

Listado de objetos de antigua industria india que ha recibido la Comisión Unuguaya para la Exposición de Madrid de 1892.

\begin{tabular}{|c|c|c|c|c|}
\hline Número & $\begin{array}{l}\text { Nombre del } \\
\text { Remitente }\end{array}$ & Localidad & Objetos & $\begin{array}{l}\text { Donación o } \\
\text { Prestación }\end{array}$ \\
\hline 22 & $\begin{array}{l}\text { Isnardi, } \\
\text { Francisco }\end{array}$ & Miguelete & $\begin{array}{l}2 \text { piedras trabajadas, } 1 \text { boleadora grande, } 3 \\
\text { fragmentos de boleadoras, } 6 \text { morteros, pequeños } \\
\text { fragmentos de alfarería. }\end{array}$ & Donación \\
\hline 184 & $\begin{array}{l}\text { Elena, } \\
\text { Esteban A. }\end{array}$ & Miguelete? & $\begin{array}{l}1 \text { piedra para triturar, } 3 \text { piedras o manos de } \\
\text { trituración, } 1\left(i^{2} ?\right) \text { martillo, } 2 \text { boleadoras. }\end{array}$ & Donación \\
\hline 444 & $\begin{array}{l}\text { Sedez, } \\
\text { Ignacio }\end{array}$ & $\begin{array}{l}\text { Punta Gorda y } \\
\text { Buceo }\end{array}$ & $\begin{array}{l}1 \text { mortero, } 3 \text { mitades de boleadoras, varios } \\
\text { raspadores, fragmentos de alfareria. }\end{array}$ & Donación \\
\hline 453 & $\begin{array}{l}\text { Sedez, } \\
\text { Ignacio }\end{array}$ & $\begin{array}{l}\text { Miguelete } \\
\text { (Capurro) }\end{array}$ & 1 punta de flecha de sílex. & Prestación \\
\hline $853-869$ & $\begin{array}{l}\text { Sienra, } \\
\text { Benjamin }\end{array}$ & Colón & 16 boleadoras redondas con ranura. & Idem \\
\hline $870-875$ & Idem & Cerro & $\begin{array}{l}6 \text { boleadoras redondas de un lado y punta de otro, } \\
\text { con ranura. }\end{array}$ & Idem \\
\hline $876-877$ & Idem & Idem & 2 boleadoras chicas. & Idem \\
\hline $878-895$ & Idem & Colón & 17 boleadoras ovaladas con ranura. & Idem \\
\hline $896-897$ & Idem & Idem & 2 boleadoras en forma de pilón. & Idem \\
\hline 898 & Idem & Cerro & Se ignora el uso. & Idem \\
\hline 902 & Idem & La teja & Se ignora el uso. & Idem \\
\hline 903 & Idem & Idem & Un disco esférico con una punta de un lado. & Idem \\
\hline $908-912$ & Idem & Cerro & 5 martillos redondos. & Idem \\
\hline $913-917$ & Idem & La Teja & 5 martillos ovalados. & Idem \\
\hline $918-924$ & Idem & Cerro & 7 pulidores redondos. & Idem \\
\hline $925-926$ & Idem & Idem & 2 pulidores ovalados. & Idem \\
\hline $937-943$ & Idem & Idem & 7 objetos, se ignora el uso & Idem \\
\hline
\end{tabular}

Tabla confeccionada por la autora, a partir de los datos extraídos de J.H. Figueira, “El Uruguay en la exposición Histórico-Americana de Madrid. Memoria” (1892: 222-231). Montevideo. Imprenta Artística de Dornaleche y Reyes. 
Teoría y Práctica de la Arqueología Histórica Latinoamericana | Año VIII. Vol. 9 | 2019

ISSN en línea: 2591-2801 | ISSN versión impresa: 2250-866X

Para la primera mitad del s. XX, Francisco Oliveras y Carlos Maeso Tognochi, realizaron recolecciones en el departamento de Montevideo. La primera colección pertenece al acervo del Museo Nacional de Antropología y la segunda se halla en mayor parte en custodia de los museos de Antropología y Maeso en Villa Soriano (dpto. de Soriano). Otras colecciones se hallan en otros museos, como ser: la colección De Freitas (Museo Nacional de Historia Natural) y la colección Figueiras del museo de la Plata. También es posible hallar artefactos o piezas de valor arqueológico, en colecciones privadas de todo el Uruguay, dado el carácter de intercambio que presenta esta actividad y quienes la realizan (Amaro, Gamas, Reboulaz, Terra y Vidal, 2014).

Las primeras intervenciones contemporáneas a nivel arqueológico, se sucedieron entre los años de 1984-1985. El departamento de Arqueología de la Comisión del Patrimonio Histórico, Artístico y Cultural de la Nación ${ }^{8}$, a través de sus técnicos y en el marco del Proyecto de Investigación Arqueológica del Departamento de Montevideo, llevan a cabo la prospección superficial intensiva de la zona costera comprendida entre la playa del Cerro y la desembocadura del río Santa Lucía.

Posteriormente López Mazz en 1987, publica los resultados de su investigación sobre los procesos de transformación en sitios arqueológicos del departamento de Montevideo. Elabora una lista de sitios arqueológicos para la costa del departamento de Montevideo basándose en el lugar de procedencia de las colecciones existentes en diferentes museos y en el reconocimiento puntual derivado de las salidas de campo: Carrasco, arroyo y zonas aledañas. afectado por industrias y urbanización. Punta Gorda/Malvín/ Buceo, Pocitos y Punta Carretas, afectado por la urbanización. Parque Rodó y Parque de Golf, afectado por la urbanización, por la forestación y por la jardinería. Arroyo Pantanoso, afectado por industrias y por urbanización. Casabó, afectado por la forestación, la deforestación y la urbanización. El material arqueológico está en superficie sobre un médano poco edafizado. Santa Catalina, afectado por la urbanización y por actividades de la zona militar. Ñames y Arenera Ferrés (cañada de los Charrúas), afectado por la forestación. El material arqueológico está en la costa de un médano edafizado; el segundo también afectado por la deforestación, la extracción de arenas. Frigorifico Ferrés (Punta Yeguas), afectado por industria. Pajas Blancas, afectado por la urbanización y por las actividades del balneario. Punta del Canario (arroyo Pajas Blancas), afectado por las actividades industriales del Astillero. El material arqueológico está en un médano poco edafizado. Playa Pascual, afectado por la urbanización y por el balneario. Punta Espinillo, acceso prohibido, zona de prácticas militares de tiro. Barra de Santa Lucía I (Y) y II (Z), afectado por las actividades de la arenera. El material arqueológico está en capa húmica el primero y el segundo caso en una capa húmico-arenosa de $1 \mathrm{mt}$. de potencia. Isla del Tigre, a pesar de la referencia de F. Oliveras, en la visita no visualizaron material arqueológico (p. 127-128).

López Mazz concluye que todos estos sitios se encuentran fuertemente alterados por diversos factores y sobre todo en la costa este del departamento, la urbanización ha llevado a que muchos ya no existan. A continuación se sintetiza en la tabla 2, la información sobre los lugares donde se han reportado hallazgos arqueológicos prehistóricos, en el departamento de Montevideo.

En 1990 el Departamento de Arqueología de la Facultad de Humanidades y Ciencias de la Universidad de la República, llevó a cabo un proyecto de investigación arqueológica en Punta Espinillos, a través de un convenio con la Intendencia Municipal de Montevideo (Baeza, 1990; Bracco, 1990; Cabrera, 1990; Lezama, 1990 y 1995 y López, 1990). 
Teoría y Práctica de la Arqueología Histórica Latinoamericana | Año VIII. Vol. 9 | 2019

ISSN en línea: 2591-2801 | ISSN versión impresa: 2250-866X

\begin{tabular}{|c|c|c|c|c|c|}
\hline $\begin{array}{l}\text { Tabla 2 } \\
\text { Lugares d }\end{array}$ & de se han reportado & tallargos & arqueológicos en el Dpto. de Montevideo & & \\
\hline Id_Sitio & Proced_Datos & $\begin{array}{c}\text { Id_ } \\
\text { Depto }\end{array}$ & Sitio & Fecha_Recol & Material \\
\hline $\begin{array}{l}\text { MA- } \\
\text { HA01 }\end{array}$ & COLECCIÓN & 01 & MALVIN & $1900-1920$ & BOLEADORAS GOLPEADORES \\
\hline $\begin{array}{l}\text { HA01 } \\
\text { MA- }\end{array}$ & $\begin{array}{l}\text { MAESO } \\
\text { COLECCIÓN }\end{array}$ & 01 & PARQUE RODO & $1900-1920$ & LITICO PULIDO \\
\hline HA05 & MAESO & & & & \\
\hline $\begin{array}{l}\text { MA- } \\
\text { HA07 }\end{array}$ & $\begin{array}{l}\text { COLECCIÓN } \\
\text { MAESO }\end{array}$ & 01 & POCITOS & 1926 & LITICO PULIDO CERAMICA \\
\hline $\begin{array}{l}\text { MA- } \\
\text { HA20 }\end{array}$ & COLECCIÓN & 01 & PUNTA CARRETAS & $1920-1930$ & LITICO PULIDO PUNTAS \\
\hline $\begin{array}{l}\text { HA20 } \\
\text { MA- }\end{array}$ & $\begin{array}{l}\text { MAESO } \\
\text { COLECCIÓN }\end{array}$ & 01 & PUNTA GORDA & 1927 & CERAMICA \\
\hline $\mathrm{HA} 21$ & MAESO & 01 & PUNIA GUREA & $192 \%$ & \\
\hline MA- & COLECCIÓN & 01 & BUCEO & $1910-1925$ & LITICO PULIDO PUNTAS \\
\hline HA03 & MAESO & & & & LASCAS CERAMICA \\
\hline $\begin{array}{l}\text { MA- } \\
\text { HA17 }\end{array}$ & COLECCIÓN & 01 & MIGUELETE (TUMULO) & 1918 & PUNTAS \\
\hline MA. & $\begin{array}{l}\text { MAESO } \\
\text { COLECCIÓN }\end{array}$ & 16 & ARAZATI & 1911 & HTICO CERAMICA \\
\hline HA48 & $\begin{array}{l}\text { MAESO } \\
\text { M }\end{array}$ & & 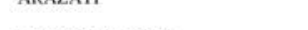 & Tा & 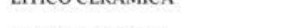 \\
\hline MA- & COLECCIÓN & 16 & PUERTO LA TUNA & 1911 & LITIO CERAMICA \\
\hline HA47 & MAESO & & & & \\
\hline $\begin{array}{l}\text { HA63 } \\
\text { MA- }\end{array}$ & $\begin{array}{l}\text { MAESO } \\
\text { COLECCIONN }\end{array}$ & 03 & LOS CERRILLOS & 1940 & LITICO PULIDO \\
\hline HA64 & MAESO & & & $19+0$ & LITICO PULIDO \\
\hline MA- & COLECCIÓN & 03 & SANTA LUCIA & 1936 & LITICO PULIDO \\
\hline HA65 & MAESO & & & & \\
\hline $\begin{array}{l}\text { MA- } \\
\text { HA66 }\end{array}$ & COLECCIÓN & 03 & ARROYO SAUCE & $1930-1950$ & LITICO PULIDO \\
\hline MA- & COLECCIÓN & 03 & ARROYO SOLIS & $1940-1950$ & CERAMICA \\
\hline HA62 & MAESO & & & & \\
\hline MA- & COLECCIÓN & 09 & SIERRA DE LAS ANIMAS & & LITICO PULIDO LASCAS \\
\hline HA44 & MAESO & & & & \\
\hline $\begin{array}{l}\text { MA- } \\
\text { HA45 }\end{array}$ & $\begin{array}{l}\text { COLECCIÓN } \\
\text { MAESO }\end{array}$ & 09 & ARROYO CASUPA & & PUNTAS \\
\hline $\begin{array}{l}\text { MA- } \\
\text { HAA47 }\end{array}$ & $\begin{array}{l}\text { BAEZA \& BOSCH } \\
\text { (1975) }\end{array}$ & 16 & LATUNA & 1972 & CERAMICA \\
\hline $\begin{array}{l}\text { MA- } \\
\text { HA46 }\end{array}$ & FERNANDEZ & 09 & BELLA VISTA & 1976 & LITICO PULIDO Y LASCADO \\
\hline MA- & MARTINEZET & 01 & ENTRE P. SAYAGO Y P. LOBOS & & \\
\hline $\mathrm{HA} 22$ & AL (1987:131) & & & & \\
\hline MA- & MARTINEZ ET & & AL NORTE ENTRE P.SAYAGO Y & & \\
\hline $\mathrm{HA} 23$ & AL (1987:131) & & P.TIGRE & & \\
\hline MA- & MARTINEZ ET & 01 & ENTRE P.TIGRE Y P.YEGUAS & & \\
\hline HA13 & AL (1987:131) & & & & \\
\hline MA- & MARTINEZ ET & 01 & PAJAS BLANCAS & & \\
\hline HA24 & AL (1987:131) & & & & \\
\hline MA. & MARTINEZ ET & 01 & P. DEL CANARIO & & \\
\hline HA25 & AL (1987:131) & & & & \\
\hline MA- & MARTINEZET & 01 & PUNTA ESPINILLO & & \\
\hline HA26 & AL $(1987: 131)$ & & & & \\
\hline $\begin{array}{l}\text { MA- } \\
\text { HA04 }\end{array}$ & LOPEZ (1987:127. & 01 & CARRASCO & & \\
\hline $\begin{array}{l}\text { MA- } \\
\text { HA21 }\end{array}$ & $\begin{array}{l}\text { LOPEZ (1987:127. } \\
128)\end{array}$ & 01 & PUNTA GORDA & & \\
\hline $\begin{array}{l}\text { HA21 } \\
\text { MA- } \\
\text { HA01 }\end{array}$ & LOPEZ (1987:127- & 01 & MALVIN & & \\
\hline $\begin{array}{l}\text { MA- } \\
\text { HA03 }\end{array}$ & LOPEZ (1987:127- & 01 & BUCEO & & \\
\hline $\begin{array}{l}\text { MA- } \\
\text { HA07 }\end{array}$ & LOPEZ (1987:127- & 01 & Pocrios & & \\
\hline MA- & $\begin{array}{l}\text { 128) } \\
\text { LOPEZ (1987:127. }\end{array}$ & 01 & PARQUE RODO & & \\
\hline HA05 & 128) & & & & \\
\hline $\begin{array}{l}\text { MA- } \\
\text { HA27 }\end{array}$ & LOPEZ (1987:127. & 01 & PARQUE DE GOLF & & \\
\hline $\begin{array}{l}\text { HA27 } \\
\text { MA- }\end{array}$ & 128) & 01 & PUNTA CARRETAS & & \\
\hline HA20 & 128) & & & & \\
\hline MA- & LOPEZ (1987:127- & 01 & ARROYO PANTANOSO & & \\
\hline MA- & LOPEZ (1987:127- & 01 & BARRIO CASABO & & \\
\hline HA16 & 128) & & & & \\
\hline $\begin{array}{l}\text { MA- } \\
\text { HA29 }\end{array}$ & $\begin{array}{l}\text { LOPEZ (1987:127- } \\
\text { 128) }\end{array}$ & 01 & SANTA CATALINA & & \\
\hline MA- & LOPEZ (1987:127- & 01 & ARENERA FERRES (CAÑADA DE & & \\
\hline HА06 & 128) & & LOS CHARRUAS) & & \\
\hline MA- & LOPEZ (1987:127- & 01 & FRIGORIFICO FERRES (PUNTA & & \\
\hline $\begin{array}{l}\text { HA13 } \\
\text { MA- }\end{array}$ & $\begin{array}{l}\text { 128) } \\
\text { LOPEZ (1987:127- }\end{array}$ & 01 & $\begin{array}{l}\text { YEGUAS) } \\
\text { PAJAS BLANCAS }\end{array}$ & & \\
\hline $\begin{array}{l}\text { MA- } \\
\text { HA24 }\end{array}$ & 128) & & & & \\
\hline MA- & LOPEZ (1987:127. & 01 & P. DEL CANARIO (Ao. PANAS & & \\
\hline HA25 & 128) & & BLANCAS) & & \\
\hline $\begin{array}{l}\text { MA- } \\
\text { HA } 30\end{array}$ & LOPEZ (1987:127- & 01 & PLAYA PASCUAL & & \\
\hline $\begin{array}{l}\text { HA30 } \\
\text { MA- }\end{array}$ & $\begin{array}{l}\text { 128) } \\
\text { LOPEZ (1987:127. }\end{array}$ & 01 & PUNTA ESPINILLO & & \\
\hline HA26 & 128) & & & & \\
\hline $\begin{array}{l}\text { MA- } \\
\text { HA31 }\end{array}$ & $\begin{array}{l}\text { LOPEZ (1987:127- } \\
\text { 128) }\end{array}$ & 01 & BARRA DE SANTA LUCIA I & & \\
\hline MA- & LOPEZ (1987:127. & 01 & BARRA DE SANTA LUCIA II & & \\
\hline $\begin{array}{l}\text { HA32 } \\
\text { MA- }\end{array}$ & $\begin{array}{l}\text { 128) } \\
\text { LOPEZ (1987:127. }\end{array}$ & 01. & ISLA DEL TIGRE. & & \\
\hline HA15 & $128)$ & & & & \\
\hline MA- & OLIVERAS & 01 & N̂MES & 1940-1950 & BOLEADORAS LASCAS \\
\hline HA33 & (MNA) & & & & PULIDOS EN GENERAL \\
\hline MA- & OLIVERAS & 01 & PUNTA GORDA & $1940-1950$ & BOLEADORAS LASCAS \\
\hline HA21 & (MNA) & & & & PULIDOS EN GENERAL \\
\hline MA- & OLIVERAS & 01 & CERRO & $1940-1950$ & BOLEADORAS LASCAS \\
\hline HA34 & (MNA) & & & & PULIDOS EN GENERAL \\
\hline MA- & OLIVERAS & 01 & PAJAS BLANCAS & $1940-1950$ & BOLEADORAS LASCAS \\
\hline $\mathrm{HA} 24$ & (MNA) & & & & PULIDOS EN GRAL. \\
\hline & & & & & CFRAMICA \\
\hline
\end{tabular}

Procesos de transformación en sitios arqueológicos en los Departamentos de Rocha y Maldonado. En: Primeras Jornadas de Ciencias Antropológicas en el Uruguay. Montevideo. Fuente: López Mazz, 1987. Extraído de Geymonat (2006). 
Para éstas últimas décadas las intervenciones arqueológicas se han concentrado sobre todo en ámbitos privados relacionados a Estudios de Impacto Arqueológico (EIArq), los cuales son monitoreados por el dpto. de Arqueología de la CPCN. A la fecha (agosto del 2018) se registraron para Montevideo, 79 intervenciones arqueológicas en la Ciudad Vieja y 21 para el resto del departamento ${ }^{9}$. Por otro lado, fue posible ampliar la bibliografía con trabajos de pre-grado y publicaciones, donde se pueden sumar algunos trabajos de investigación, relacionados al relevamiento de entidades culturales materiales y/o su carácter patrimonial.

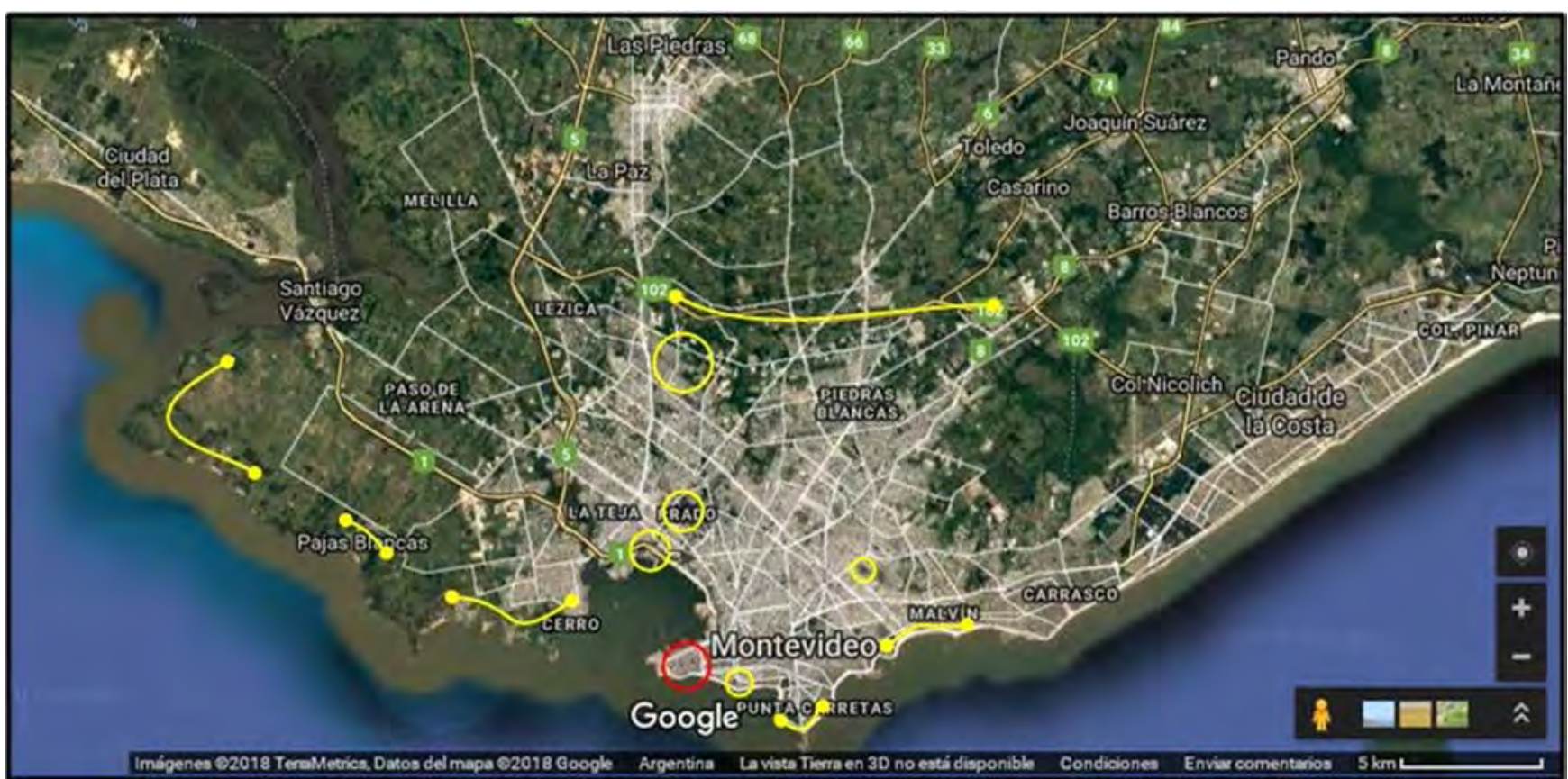

Figura $V$. Imagen satelital donde se encuentra marcado en amarillo las áreas de intervenciones arqueológicas hasta la actualidad (Agosto 2018), en rojo se señala el casco histórico fundacional de Montevideo- hoy Ciudad Vieja, donde se concentran la mayoría de las intervenciones. Fuente: Departamento de Arqueología- Comisión del Patrimonio Cultural de la Nación, Publicaciones, Investigaciones Independientes y Monografías de Grado. Recuperado de: Google earth, 2018.

\section{La Arqueología y su aporte a la identidad barrial}

Es posible reconocer dentro del espacio social diferentes escalas: el espacio macro, el cual brinda una idea del lugar geopolítico y geográfico del asentamiento: lo rural y lo urbano. El espacio medio relacionado a la disposición de las estructuras en el entorno urbano y la simbolización social adjudicada. Existiendo un componente dicotómico, ejemplo de ello son los espacios públicos y privados, abiertos y cerrados, de ocupación y descarte. Lo micro se halla dentro de la forma urbana y relacionado a las estructuras dentro de ella (Curbelo, 1999).

Desde hace algunos años se han realizado trabajos no sistematizados de relevamiento en diferentes zonas capitalinas. Producidos a raíz de intervenciones puntuales, como ser: hallazgos fortuitos o por el interés de los vecinos en profundizar sobre su historia local. Esto ha derivado en el estudio del potencial 
arqueológico de algunas de estas áreas; las cuales conservan aún hoy vestigios materiales de su historia, como de su desarrollo.

Los hallazgos ocasionales de vestigios materiales, informados por la sociedad civil, pueden presentarse como de escasa relevancia, debido a la reducida información a nivel social de cómo proceder ante los mismos; esto se produce sobre todo en las áreas externas al casco histórico-fundacional de Montevideo (Ciudad Vieja).

Los casos presentados a continuación son los de mayor representatividad y fueron relevados por la autora a lo largo de varios años, intentando rescatar el mayor cúmulo de datos posible:

1) En la zona costera del departamento, entre los barrios Punta Carretas y Parque Rodó, frente al club de golf. Allí se reportaron en un sitio web el hallazgo de petroglifos (aún en estudio), los cuales fueron hallados por un vecino asiduo a los paseos por el área (ver figura VI).

2) En la zona de Paso Molino ${ }^{10}$, donde aún se halla en pie la única posta de diligencia (segunda mitad del s.XIX), se descubrieron un aljibe y un marco de puerta, el cual presenta tipología de fines del s. XVIII. Estos vestigios arqueológicos están en proceso de análisis tipológico, así como su asociación con los molinos de agua de los jesuitas ${ }^{11}$.

3) En el barrio La Unión, se está llevando a cabo una investigación relacionada a estructuras monumentales subterráneas, la historia oral hace mención a la existencia de túneles; tras las investigaciones realizadas (sobre todo bibliográficas) se plantea la hipótesis sobre la construcción de enormes sistemas de captación de agua (cisternas), realizados por dos maestros catalanes: Mayol y Fontgibell. Tras la recopilación de más información y la realización de estudios geofísicos, se detectaron anomalías en la Plaza de la Restauración.

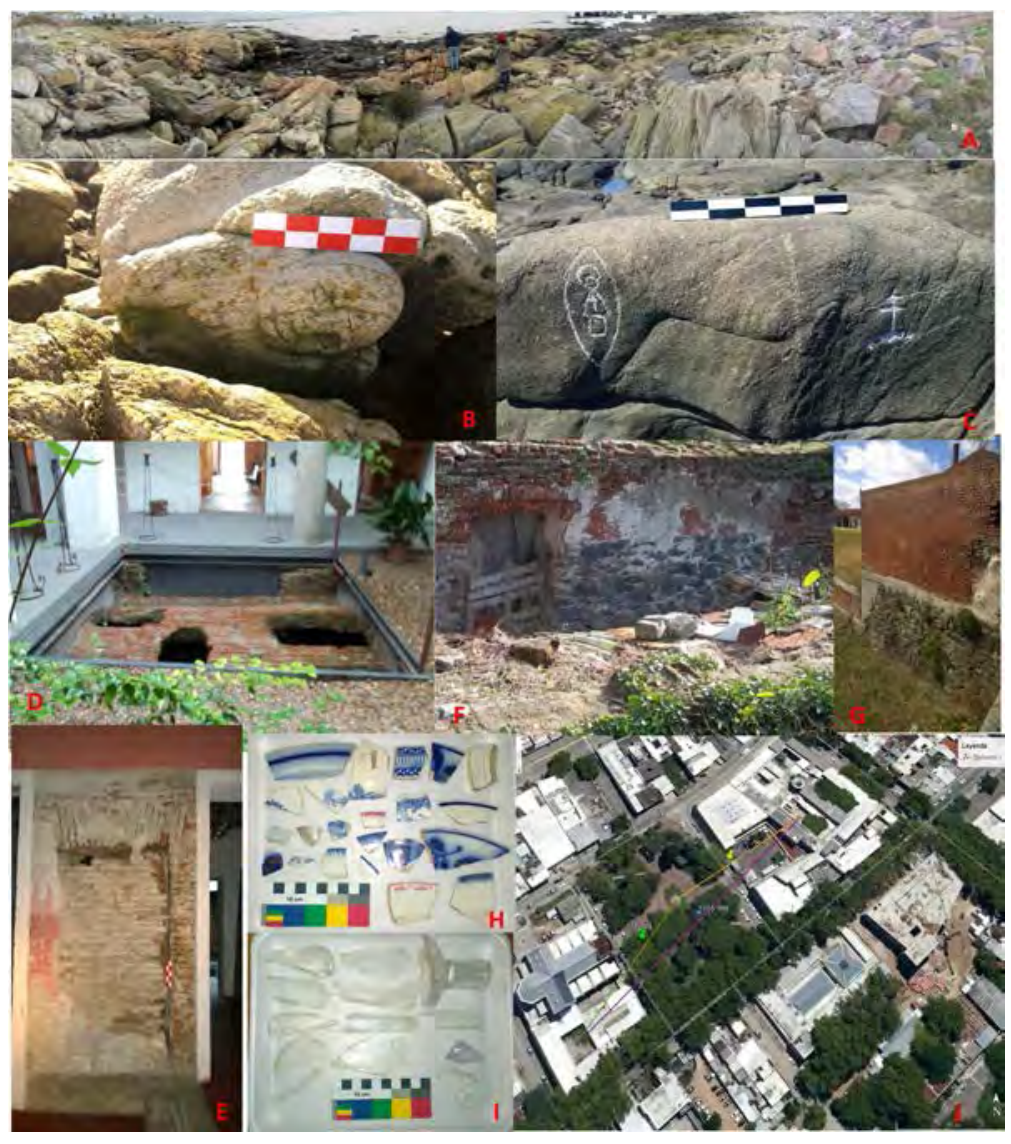

Figura VI. Imágenes de relevamiento en distintas zonas de Montevideo. Punta Carretas-Parque Rodó (A, B y C); Paso Molino (D, E, F y G); La Unión (H, I y J). Imágenes pertenecientes al archivo particular de la autora entre los años 2014-2018. 
El paisaje urbano histórico plantea ir más allá de la conservación del propio entorno físico para abarcar también lo inmaterial, proporcionando sostenibilidad a las intervenciones a nivel cultural y socio-económico dentro de las comunidades locales, donde cabría incorporar el patrimonio material.

Es así, que es muy frecuente presenciar la extracción de materialidades de carácter histórico, por obras público/privada (ver figura VII); entre las cuales se pueden mencionar: a) obra del ensanche de la av. Belloni ${ }^{12}$; b) subsuelo en una casa de la calle Andes esq. Soriano, donde se hallaron estructuras en arco para sobre nivelar la edificación; c) demolición en la av. Agraciada de una de las casas referente de la zona; d) retiro de rieles de tranvía por repavimentación frente al Palacio Legislativo ${ }^{13}$ y en barrio Palermo.

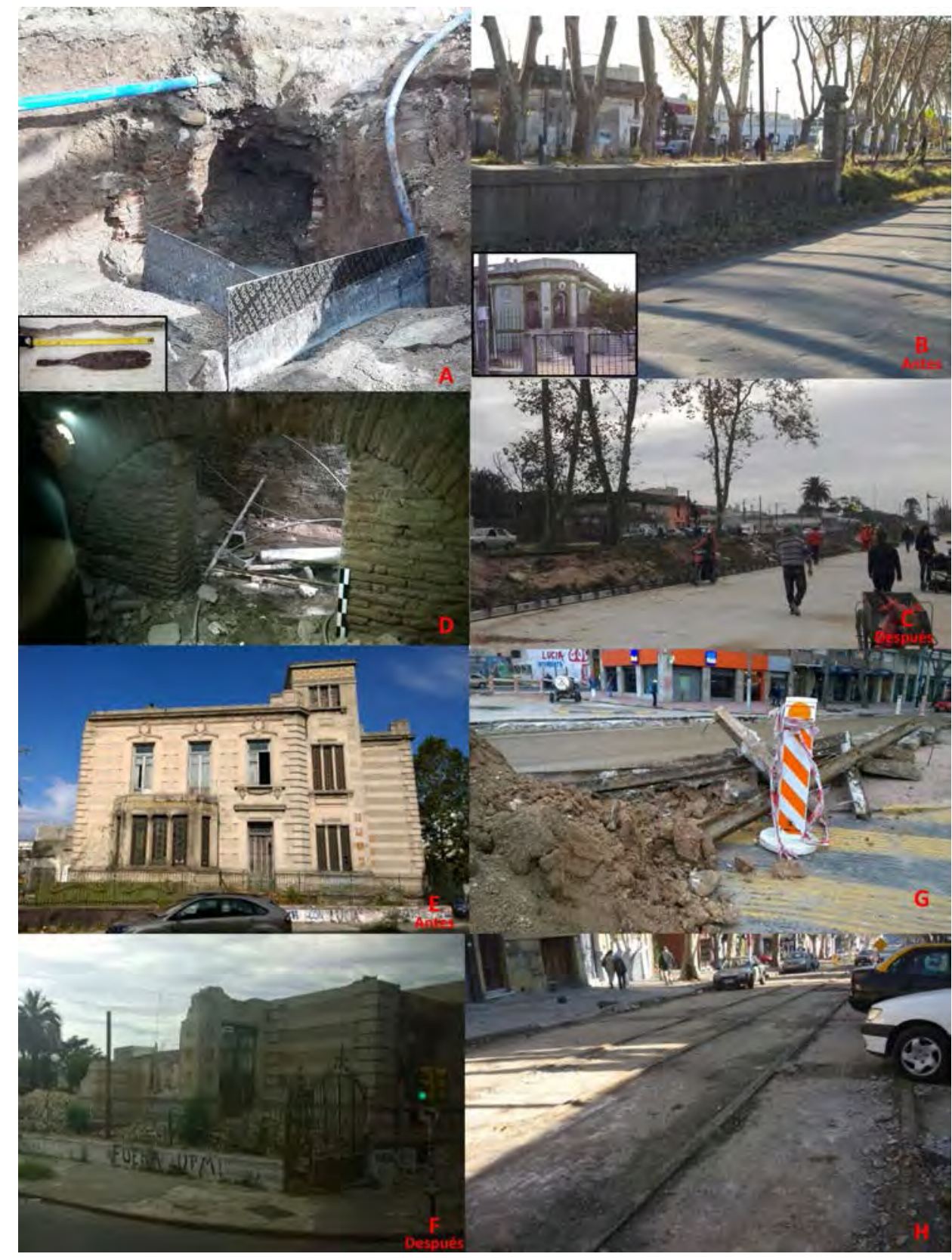

Figura VII. Imágenes de relevamiento en distintas zonas de Montevideo. Barrios: Manga (A, B y C); Centro (D); Reducto (E y F); Aguada (G); Palermo $(\mathrm{H})$. La imagen A, fue cedida por la Ing. Zenia Rodríguez (Intendencia de Montevideo) en el 2019; la imagen $\mathrm{H}$, fue cedida por la Sra. María José Vidal en el año 2015. El resto de las imágenes pertenecen al archivo particular de la autora entre los años 20142019. 


\section{Consideraciones Finales}

Se plantea un aporte a la construcción social y cultural de la población, por medio de la arqueología. La cual estudia y analiza las materialidades y su contextualidad espacial y temporal. En contextos más complejos como las urbes y su cambio continuo del uso del espacio; es admitida una observación detenida al momento de gestionar los espacios históricos.

Mediante la revisión bibliográfica histórica y arqueológica de las zonas periféricas de Montevideo se ha podido ilustrar la relevancia y la necesidad de implementar nuevas líneas de investigación. Las cuales permitirían articular la historia material e inmaterial dentro de los barrios, formando nexos con la identidad de sus habitantes locales y foráneos (estudio, trabajo) considerando también la trasmisión oral inter-generacional.
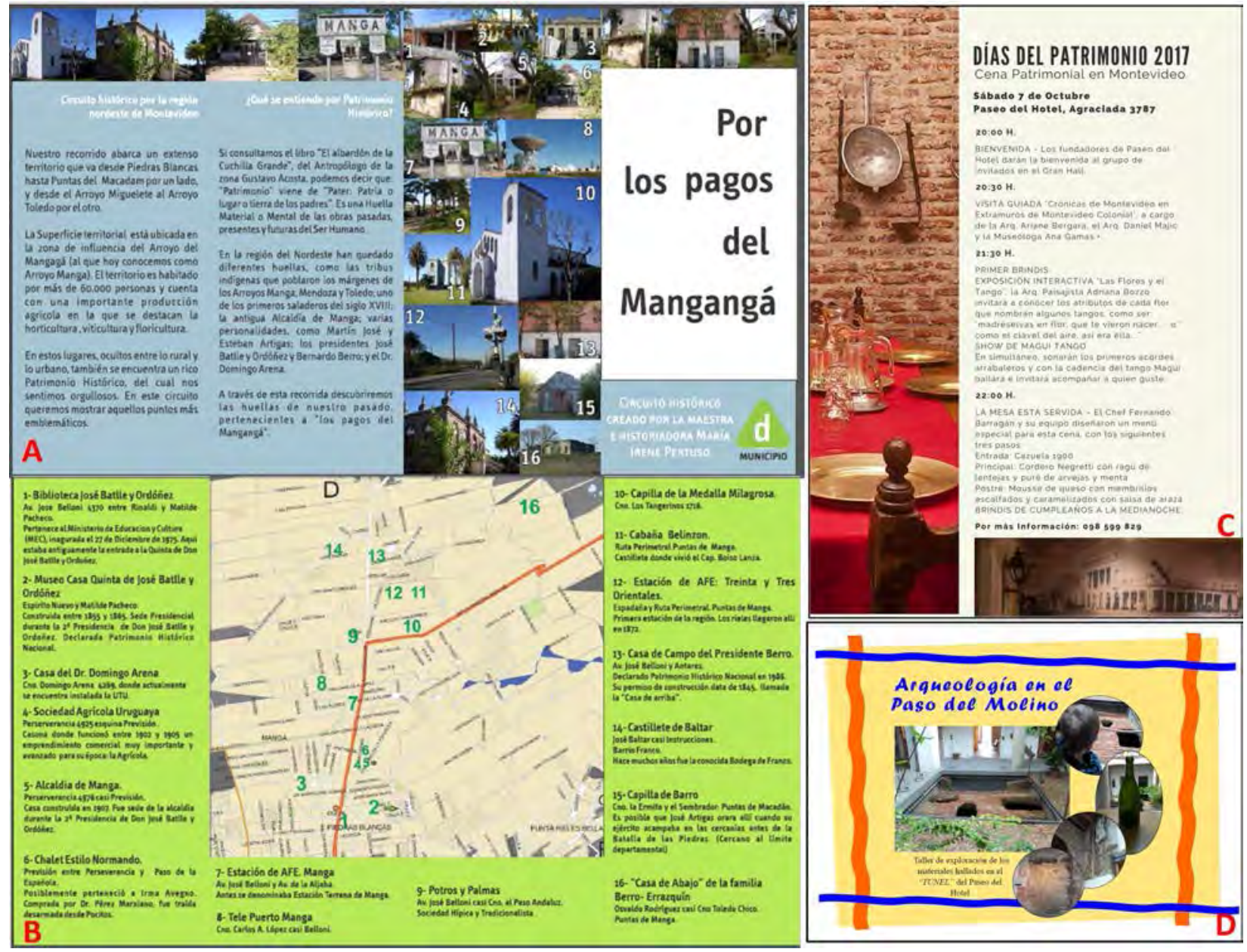

Figura VIII. Ejemplos de Difusión del patrimonio local mediante folletería y puestas en valor específicas. Imagen A y B diseñado por la Maestra Irene Pertuso. Recuperado de: http://municipiod. montevideo.gub.uy/sites/municipiod/files/recorrido_con_irene_pertuso.pdf (consultado abril 2019). Imagen $\mathrm{C}$, cena diseñada en base a los productos que se plantaban a orillas del miguelete entre los s. XVIII - XX. Imagen cedida por la Arq. Ariane Bergara. Imagen D, diseño de folletería realizado por la autora, Taller de Arqueología para niñ@s. 
Los relevamientos asistemáticos expuestos, intentaron visibilizar - en parte - la problemática de la pérdida de información sustancial para la construcción de la identidad local; evidenciando la necesidad de un abordaje metodológico. El proceso de análisis de estos sitios se realiza a través de una doble instancia: aportando elementos necesarios para su conocimiento y articulando la información obtenida (ver figura VIII).

En este sentido, es necesario crear y gestionar políticas acordes con los cambios urbanísticos, suministrando herramientas y políticas participativas para la sociedad civil y de gestión empresarial, con destino al trabajo en conjunto. Junto a ello aunar esfuerzos en la interpretación inter y multidisciplinaria del patrimonio.

\section{Notas}

${ }^{1}$ Ciencias como la Geografía han incursionado en líneas de estudio relacionadas a la geografía urbana, enfocadas al estudio de las tramas urbanas (villas, pueblos, y ciudades), desde su emplazamiento, situación actual, evolución y patrón de asentamiento. La Geografía Urbana en una sub-disciplina de la Geografía Humana. Estudia ciudades y pueblos; incluidas sus características internas, estructuras, relaciones espaciales interna y externamente. Recuperado de: https://www.ecured.cu/Geograf\%C3\%ADa urbana (consultado abril 2019).

2 Recomendación del 10 de noviembre del 2011. Recuperado de: http://portal.unesco.org/es/ev.phpURL ID=48857\&URL DO=DO TOPIC\&URL SECTION=201.html (consultado abril 2019)

${ }^{3}$ Recomendación Conjunto histórico/ciudad histórica de la UNESCO del año 1976. Recuperado de: http://portal.unesco.org/es/ev.php-URL ID=48857\&URL DO=DO TOPIC\&URL SECTION=201.

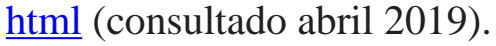

4 “(...) Por lo que mira a fortificar los puestos de Maldonado y Montevideo os Encargo asimismo deis la providencia que juzgareis puede ser más efectiva a su logro, para que ni Portugueses, ni otra nación alguna se apodere ni fortifique estos parajes y que solicitéis poblarlos y fortificarlos vos en la forma y con la brevedad que pudieredes dandome quenta de lo que sobre esto obrareis”. Real cédula al gobernador de Buenos Aires sobre población y fortificación de Montevideo y Maldonado. 13 de noviembre de 1717. Archivo General de la Nación, Bs. As., división Colonia, legajo de reales cédulas n4. Fuente: Azarola Gil, 1976, pp. 219-220.

${ }^{5} \mathrm{Si}$ bien Pérez Montero no específica en este apartado a que se refiere con la colina, si hace referencia más adelante a la cuchilla. Se refiere además a las zonas del relieve más altas, que ofician como divisorias de agua.

${ }^{6}$ Según decreto del 17 de Noviembre de 1840, suscripto por Rivera y su ministro Francisco A. Vidal, donde revalidan lo dispuesto lo la Ley Segunda, Título 17, Libro IV de las Leyes de Indias (Arredondo, 1959, p.141).

${ }^{7}$ Agave americana, planta utilizada para conformar una especie de cerco vivo.

${ }^{8}$ Unidad Ejecutora del Ministerio de Educación y Cultura (M.E.C.). Hoy Comisión del Patrimonio Cultural de la Nación (CPCN). Montevideo- Uruguay.

${ }^{9}$ Fuente: Departamento de Arqueología de la Comisión del Patrimonio Cultural de la Nación (MontevideoUruguay).

${ }^{10}$ El topónimo Paso Molino proviene del primer molino que tuvo Montevideo desde 1747, perteneciente a la Compañía de Jesús; tan importante fue este mojón para el área, que ya desde ese momento se referenciaba en los mapas como “al llegar al Molino o al enfrentar el Molino” (Ferres, 1916, p.305). Las 
grandes dicotomías de la historia se dan en todo momento, ya que ninguno de los barrios comprendidos en esa área conservó el nombre antiguo; sin embargo, actualmente esa zona es conocida y sus habitantes adoptan como suyo el nombre de Paso Molino, siendo punto indiscutible de referencia capitalino.

${ }^{11}$ Según Ferres (1919) los Jesuitas llegaron a tener “(...) casa de altos con sala, alcoba, cocina, cuarto y rancho, dos molinos, la tahona antigua, una nueva en construcción, el horno de ladrillos, algún corambre (...)” según el inventario de lo existente en el predio” (p.309) en la zona de Paso Molino.

${ }^{12}$ Se halló estructura de ladrillo, espátula para charre (tipo de carruaje de ocasión) y relevamiento de muro perimetral de casona s. XIX-XX.

${ }^{13}$ La compañía La Trasatlántica realizaba el recorrido por la av. Agraciada, desde el Centro a Paso Molino.

\section{Referencias bibliográficas}

AMARO, C., GAMAS, A., REBOULAZ, I., TERRA, M. E., y VIDAL, M. J. (2013-2014). Conociendo lo recolectado. Registro y puesta en valor del acervo arqueológico de colecciones privadas inéditas, en los departamentos de Canelones y Paysandú. Informe PAIE. Docente orientador: Ing. Agr. Jorge Baeza. Montevideo: Facultad de Humanidades y Ciencias de la Educación.

AMEGHINO, F. (1912). Noticias sobre antigüedades indias de la Banda Oriental (1877). En: Obras Completas. Vol . 1 (pp. 147-206). Mercedes: Imprenta La Inspiración.

ARREDONDO, H. (1951). Civilización del Uruguay: aspectos arqueológicos y sociológicos (16001900). Tomo 1. Montevideo: Instituto Histórico y Geográfico del Uruguay.

ARREDONDO, H. (1959). El transporte a sangre en el antiguo Montevideo y su extensión al interior. En: Apartado de Anales Históricos de Montevideo. Tomo 2. Montevideo: Publicación del Museo y Archivo Histórico Municipal.

AZAROLA GIL, L. E. (1976). Los orígenes de Montevideo (1607-1749). Montevideo. Comisión de Actos Conmemorativos de los 250 años de la fundación de Montevideo.

BAEZA, J. (1990). Análisis preliminar de la evolución del paisaje vinculado con los asentamientos indígenas de la región. Punta Espinillos. Montevideo: Facultad de Humanidades y Ciencias.

BARACCHINI, H. y ALTEZOR, C. (2008). Historia del ordenamiento territorial en el Uruguay: república liberal del siglo XIX (1830-1903) y sus antecedentes coloniales. Montevideo: Ed. Trilce.

BARRIOS PINTOS, A (1971). Los Barrios de Montevideo ( I ). Montevideo: Ed. Nuestra Tierra.

BARRIOS PINTOS, A. (1998). La Ciudad Vieja (2). Los Barrios de Montevideo. Montevideo: Intendencia de Montevideo.

BAUZÁ, F. (1895). Historia de la dominación española en el Uruguay. Tomo 1. Montevideo: Ed. Barreiro y Ramos.

BOLLO, S. (1897). Manual de historia de la República Oriental del Uruguay. Primera y Segunda Parte (1492-1830). Montevideo: Ed. Barreiro y Ramos.

BRACCO, R. (1990). Un fechado 14C en Punta Espinillos. Montevideo: Facultad de Humanidades y 
Teoría y Práctica de la Arqueología Histórica Latinoamericana | Año VIII. Vol. 9 | 2019

ISSN en línea: 2591-2801 | ISSN versión impresa: 2250-866X

Ciencias.

CABRERA, L. (1990). Reseña histórica de Punta Espinillo. Montevideo: Facultad de Humanidades y Ciencias.

CAPILlAS DE CASTELLANOS, A. (1971). Montevideo en el siglo XVIII. Montevideo: Ed. Nuestra Tierra.

CURBELO, C. (1999). Análisis del uso del espacio en San Francisco de Borja del Yí (Depto. de Florida, Uruguay). En: Zarankin, A. y Acuto, F. Sed Non Satiata. Teoría Social en la Arqueología Latinoamericana Contemporánea. (pp. 97 - 116). Buenos Aires.

DE LA SOTA, J. M (1965). Historia del territorio oriental del Uruguay. Tomo II. Montevideo: Biblioteca Artigas, Colección de clásicos uruguayos. Vol.73.

DE MARÍA, I. (1872). Compendio de la historia de la República Oriental del Uruguay: comprendiendo el descubrimiento, conquista y población del Río de la Plata. Montevideo: $3^{\circ}$ Edición.

DE MARÍA, I. (1883). Anales de la defensa de Montevideo 1842-1851. Tomo I. Montevideo: Imprenta El Ferro-Carril.

FIGUEIRAS, J. H. (1892). Los primitivos habitantes del Uruguay. En: El Uruguay en la Exposición Histórico-Americana de Madrid. Memoria de los trabajos realizados por la Comisión Nacional encargada de organizar los elementos de concurrencia. Montevideo: Imprenta artística de Dolmeneche y Reyes.

GAMAS, A. (2015). El análisis por Espectrometría de Fluorescencia de Rayos X: Aplicación en Arqueología. Un ejemplo, caracterización sobre enlucidos (revoques). Trabajo de pre-grado en Técnicas de Investigación en Arqueología. Montevideo: Facultad de Humanidades y Ciencias de la Educación- Universidad de la República. Geymonat, J. (2006). Estudio de Impacto Arqueológico: Anillo Perimetral Vial de Montevideo. Recuperado de: versión digital cedido por la autora a A. Gamas.

GIMÉNEZ RODRÍGUEZ, A. (2016). Éramos tan fuertes. Historia y misterios de las murallas de Montevideo. Montevideo: Ed. Cruz del Sur y Linardi y Risso.

LEZAMA, A. (1990). Las industrias líticas de Punta Espinillo. Departamento de Montevideo. Montevideo: Facultad de Humanidades y Ciencias.

LEZAMA et. al (1995). Arqueología experimental: Talla de sílex en Punta Espinillo. En: Arqueología en Uruguay. VIII Congreso de Arqueología Uruguaya. Maldonado.

LÓPEZ MAZZ, J. M. (1987). Procesos de transformación en sitios arqueológicos de los departamentos de Rocha y Montevideo. En: Primeras Jornadas de Ciencias Antropológicas en el Uruguay. Montevideo.

LÓPEZ MAZZ, J. M. (1990). Relevamiento, diagnóstico y rescate arqueológico en el área de unta Espinillo (Dpto. de Montevideo). Montevideo: Intendencia de Montevideo y Facultad de Humanidades.

PÉREZ MONTERO, C. (1942). La calle del 18 de Julio (1719-1875). Antecedentes para la historia de 
Teoría y Práctica de la Arqueología Histórica Latinoamericana | Año VIII. Vol. 9 | 2019

ISSN en línea: 2591-2801 | ISSN versión impresa: 2250-866X

la ciudad nueva. Montevideo: Imprenta El Siglo Ilustrado.

PROUDFOOT (1981). Archaeological space. In: Journal of Historical Geography. Vol.7, 303-306.

REYES ABADIE, W. (1977). Historia Uruguaya. Segunda Serie. Montevideo: Ed. Banda Oriental.

RUIZ ZAPATERO, G. y BURILLO MOZOTA, F. (1988). Metodología para la investigación en arqueología territorial.

SÁNCHEZ YUSTOS, P. (2009). El paleolítico antiguo en la Cuenca del Duero. Instrumentos teóricos para el desarrollo interpretativo de arqueología económica. Tesis Doctoral inédita. Valladolid. Universidad de Valladolid.

SÁNCHEZ YUSTOS, P. (2010). Las dimensiones del paisaje en arqueología. En: Munibe AntropologíaArkeología. Vol. 61, 139-151. Recuperado de https://www.academia.edu/12032695/Las dimensiones del paisaje en Arqueolog\%C3\%ADa. Landscape dimensions in Archaeology

SCHÁVELZON, D. (2018).Manual de Arqueología Urbana: técnicas para excavar Buenos Aires. Buenos Aires. Centro de Arqueología Urbana, Instituto de Arte Americano “M. J. Buschiazzo”, Buenos Aires: Facultad de Arquitectura, Diseño y Urbanismo, Universidad de Buenos Aires.

TRONCOSO, A. (2008). Arquitectura del paisaje y relacionalidad del espacio. En: Puentes hacia el pasado: reflexiones teóricas en arqueología. Eds. D. Jackson, D. Salazar, A. Troncoso. Serie monográfica de la Sociedad Chilena de Arqueología y Departamento de Antropología de la Universidad de Chile. Santiago de Chile. Ed. LOM.

UNESCO (2013). Nueva vida para las ciudades históricas: el planteamiento de los paisajes urbanos históricos. Biblioteca Digital Unesco. CLT-2013/WS/11

VALLADAO, T. B. (2001). Arqueologia de contrato. Metodologias de prospeçcão para áreas urbanas. Santa Cruz do Sul. Revista do CEPA. Vol. 25 (33), 73-79

ZARANKIN, A. (1994). Arqueología urbana: Hacia el desarrollo de una nueva especialidad. En: Arqueología Histórica en América Latina. Vol. 2. Columbia, S.C. U.S.A.The University of South Carolina.

Recibido: 30 de abril de 2019

Aceptado: 17 de julio de 2019 